\title{
O movimento global pela saúde dos povos. $O$ que é o Movimento pela Saúde dos Povos?
}

\author{
The global People's Health Movement. What is the People's Health \\ Movement?
}

Fran Baum', David Sanders ${ }^{2}$, Ravi Narayan $\mathbf{3}$

DOI: 10.1590/0103-11042020S101

A luta pela saúde é uma luta por um mundo mais justo.

Dr. Amit Sengupta

\section{Introdução}

O Movimento pela Saúde dos Povos (MSP) é uma rede global formada no ano 2000 e que envolve trabalhadores de saúde, organizações da sociedade civil, redes de temas específicos, acadêmicos, pesquisadores e ativistas de países de baixa, média e alta renda. Sua atividade é realizada localmente através de círculos nacionais e globalmente através de uma série de campanhas. A base de todas as suas atividades é o compromisso com a Saúde para Todos, conforme interpretado na Organização Mundial da Saúde (OMS), em 1978, e na Declaração de Alma-Ata sobre Atenção Primária à Saúde (APS) ${ }^{1}$. Essa Declaração apresentou uma visão abrangente para a APS, na medida em que relacionou os serviços de saúde à organização mais ampla da sociedade, exigindo uma nova ordem econômica internacional que beneficiaria os países em desenvolvimento, potencializando a participação democrática na saúde e chamando para a ação em contextos sociais e ambientais que aumentam os riscos de doenças. Os serviços de saúde deveriam ser multidisciplinares, estar em sintonia com as necessidades locais e enfatizar a prevenção de doenças e a promoção da saúde. A redução das desigualdades entre grupos dentro das nações e entre nações foi considerada vital e reconhecida no chamado à Saúde para Todos, no ano 2000. A resistência a essa concepção visionária da saúde foi rápida, e o apelo à APS seletiva ocorreu logo após ${ }^{2}$. Nas décadas seguintes a 2000, o neoliberalismo se converteu

1Flinders University, Southgate Institute Bedford Park, Australia. fran.baum@flinders.edu.au

2 University of Western Cape (UWC), School of Public Health (in memoriam) - Cape Town, South Africa.

${ }^{3}$ Society for Community Health Awareness,

Research and Action (Sochara) - Karnataka, India. na força motriz dominante por trás das políticas públicas ${ }^{3}$, e o ajuste estrutural das economias dos países de baixa e média renda foi fortemente promovido pelo Banco Mundial e pelo Fundo Monetário Internacional (FMI) ${ }^{4}$. Esses desenvolvimentos levaram a uma crescente preocupação entre os ativistas da saúde, e ficou claro que a Saúde para Todos não seria alcançada até o ano 2000 e que as desigualdades econômicas, na realidade, estavam aumentando ${ }^{5}$. Além disso, ficou claro que a OMS havia retirado o forte apoio à APS sob a liderança do Dr. Halfdan Mahler, e impulsionado um declínio contínuo nas contribuições financeiras dos Estados membros. A OMS havia indicado recentemente sua intenção de considerar parcerias público-privadas ${ }^{6}$ no financiamento de suas operações. Nesse contexto, e como contrapeso às tendências perturbadoras da OMS e das sucessivas Assembleias Mundiais de Saúde, foi planejada a primeira Assembleia de Saúde dos Povos (ASP 1). 


\section{Origens do movimento}

Oito redes e organizações (descritas no quadro 1) se uniram para planejar a primeira Assembleia de Saúde dos Povos. Todas elas advogaram por diferentes aspectos da Saúde para Todos, e algumas haviam se comprometido junto à OMS com pautas mais específicas, como para promover políticas racionais de medicamentos, APS integral, direitos do consumidor na assistência médica, direitos sexuais e reprodutivos, regulação dos substitutos do leite materno e abordagem sobre os determinantes sociais e econômicos da saúde.

Quadro 1. Redes e organizações fundadoras do Movimento pela Saúde dos Povos

Conselho Internacional de Saúde dos Povos - O International People' Health Council (IPHC) é uma coalizão de movimentos de saúde de base que emergiram de situações de luta popular (incluindo África do Sul, Nicarágua, Palestina, Bangladesh).

Internacional de Consumidores - A Consumers International (Cl) é uma grande rede de 250 organizações membros em 120 países que busca obter mudanças na política governamental e no comportamento corporativo, enquanto sensibiliza sobre os direitos e responsabilidades dos consumidores.

Internacional de Ação em Saúde - A Health Action International (HAl) pressiona governos e organizações internacionais (como a OMS) a formular códigos, aprovar resoluções e desenvolver políticas para garantir que as pessoas que precisam tenham acesso a medicamentos adequados, seguros e acessíveis, e que eles sejam utilizados racionalmente. Supervisiona o comportamento antiético da indústria, incluindo as práticas de vendas e promoção de empresas farmacêuticas.

Rede do Terceiro Mundo - A Third World Network (TWN) é um grupo transnacional de políticas alternativas e uma rede internacional de organizações que produzem e divulgam análises, propostas e ferramentas de informação relacionadas à sustentabilidade ecológica, ao desenvolvimento e às relações Norte-Sul7.

Rede Asiática de Ação Comunitária em Saúde (Achan) - A Asian Community Health Action Network (Achan) é uma rede de iniciativas e instituições de saúde comunitária que buscam difundir uma filosofia de atenção à saúde com base na comunidade e no desenvolvimento humano autossuficiente para os pobres e oprimidos ${ }^{8}$.

Rede Global de Direitos Reprodutivos da Mulher - A Women's Global Network for Reproductive Rights (WGNRR) defende a saúde e os direitos sexuais e reprodutivos em todo o mundo. Com sede no sul global, trabalha com os direitos, a justiça e os marcos feministas e têm um status consultivo no Economic and Social Council (Ecosoc) 9 .

Fundação Dag Hammarskjold (DHF) - foi criada em 1961 como o memorial nacional sueco do falecido Dr. Dag Hammarskjold, Secretário Geral das Nações Unidas. Desempenha um papel catalisador na promoção de ideias inovadoras, debates sobre desenvolvimento, segurança e democracia e apoiou o processo preparatório da Assembleia de Saúde dos Povos e sua organização10.

Gonoshasthaya Kendra (GK) é um programa de desenvolvimento de saúde comunitária em Bangladesh, iniciado durante a guerra pela independência nacional. A GK organizou a primeira Assembleia Mundial da Saúde dos Povos em seu campus rural, em Savar, Bangladesh"1.

O anúncio de uma Assembleia de Saúde dos Povos (ASP) claramente comoveu muita gente, resultando na presença de 1.500 pessoas de mais de 90 países na primeira ASP. No período anterior à Assembleia, ativistas de várias redes e países escreveram a Carta de Saúde dos Povos, que foi revisada e logo aprovada pelos delegados na Assembleia. Desde a ASP 1, três outras Assembleias foram realizadas: Cuenca, Equador (2005), Cidade do
Cabo, África do Sul (2012) e Savar, Bangladesh (2018). (Consulte https://www.youtube.com/ watch?v=Kmm5Hj0HNWA para obter um vídeo que descreve o evento e fornece informações sobre o MSP na voz de seus ativistas).

Essas Assembleias são, de fato, o fórum de condução definitivo do MSP, onde as prioridades e direções do Movimento são polidas e respaldadas. São eventos inspiradores, que motivam os seguidores do MSP. 
Em 2019, o MSP conta com as seguintes redes como afiliadas (nomes no idioma original):

- Medicus Mundi Rede Internacional - MMI

- Viva Salud, Bélgica

- Health Poverty Action - HPA, Reino Unido

- Associação Latino-Americana de Medicina Social - Alames

- Gonoshasthaya Kendra, GK - Centro de Saúde Popular, Bangladesh

- Health Action International - HAI

- Third World Network - TWN

- HAI Ásia Pacífico

- International Baby Food Action Network - IBFAN

- Resource Group for Women and Health - Sama

- Global Justice Now

- Centro Brasileiro de Estudos de Saúde - Cebes

- Community Working Group on Health, CWGH, Zimbábue

- Public Services International

\section{A ideologia e a visão do Movimento pela Saúde dos Povos}

A ideologia e a visão do MSP se baseiam nas suas redes e organizações originais. A Carta de Saúde dos Povos (CSP), elaborada no ano anterior à ASP 1, em dezembro de 2000, consagra a visão do MSP. Essa Carta foi adotada na ASP 1. Posteriormente, a Carta foi refinada e adaptada às novas circunstâncias, sendo enriquecida por declarações resultantes das posteriores Assembleias de Saúde dos Povos em resposta a problemas críticos de saúde global (ver quadro 2).

\section{Contexto global da saúde: análise das causas estruturais dos problemas de saúde e da desigualdade}

A análise do contexto global pelo MSP sublinha que o atual paradigma de desenvolvimento, caracterizado pelo individualismo, antropocentrismo e capitalismo neoliberal, é a base das crescentes iniquidades em saúde. Essa análise indica que os governos de países de alta renda, em estreita colaboração com empresas transnacionais, estão promovendo políticas neoliberais para administrar a crise contemporânea do capitalismo globalizado em consonância com os interesses da classe capitalista transnacional. Com a ajuda de um conjunto de acordos unilaterais de 'comércio e investimento’, essas políticas estão sendo aceitas ou forçadas aos governos dos países de baixa e média renda e suas populações, bem como à maioria nos países de alta renda. As políticas nacionais resultantes, que incluem austeridade fiscal e desregulamentação da atividade econômica, têm consequências de longo alcance para as condições sociais que moldam a saúde das pessoas e também para a abordagem e o financiamento dos cuidados de saúde. O MSP observa que essas políticas estão piorando os determinantes fundamentais da saúde e paralisando progressivamente a infraestrutura de saúde e a prestação de serviços. Elas também estão incentivando os governos nacionais a renunciarem à sua responsabilidade pela saúde pública, enquanto marcam o início da privatização de bens públicos, incluindo serviços de saúde, geralmente através da introdução de esquemas de seguro. O MSP 
também aponta a natureza patriarcal, racista e homofóbica da ideologia atualmente dominante, que também serve para aumentar a discriminação e afetar a saúde das pessoas.
O MSP aponta para ameaças à saúde humana e planetária representadas por conflitos, migração forçada em massa e um clima que muda rapidamente.

Quadro 2. A visão do Movimento pela Saúde dos Povos

A visão desenvolvida na Carta de Saúde dos Povos de 200012 guia o movimento. O desenvolvimento equitativo e ecologicamente sustentável e a paz são o núcleo da nossa visão de um mundo melhor: um mundo em que uma vida saudável para todos seja uma realidade; um mundo que respeita, aprecia e celebra toda a vida e diversidade; um mundo que permite o florescimento dos talentos e habilidades das pessoas para enriquecerem-se mutuamente; um mundo em que as vozes das pessoas guiam as decisões que moldam nossas vidas. Existem recursos mais que suficientes para alcançar essa visão'12. O MSP vê a saúde como um direito humano que prevalece sobre as preocupações econômicas e políticas. O movimento baseia-se no entendimento de que a ação sobre os determinantes sociais, econômicos, políticos, comerciais e ambientais mais amplos da saúde é fundamental para a saúde e a equidade. Promove a atenção primária à saúde integral como a base dos sistemas de saúde, e a Declaração da ASP 4 estabelece: "Queremos sistemas de saúde pública equitativos que sejam universais, adequados ao contexto, integrados e integrais - que não sejam discriminatórios, desempoderadores, privados ou com a finalidade de lucro. Sistemas que proporcionam uma plataforma apropriada para ação sobre os determinantes sociais da saúde, incluindo uma mudança radical nas estruturas de poder existentes".

O MSP promove, como fundamental para uma sociedade saudável, a participação democrática e processos de tomada de decisão transparentes, responsáveis e com equidade de gênero, por meio de uma forte organização e movimento dos povos.

Fonte: Carta para a Saúde dos Povos ${ }^{\mathbf{2}}$, Declaração de Cuenca13, Chamada à Ação da Cidade do Cabo ${ }^{\mathbf{1 4}}$. A luta pela saúde é a luta por um mundo mais justo, equitativo e solidário - Declaração da Quarta Assembleia da Saúde dos Povos ${ }^{15}$.

Uma das características exclusivas do MSP é que suas posições ideológicas são desenvolvidas através de uma dialética entre análise acadêmica e reflexão sobre a experiência vivida. Isso é visto com mais clareza nas Assembleias, onde são apresentadas pesquisas e análises da economia política da saúde contemporânea, juntamente com testemunhos de pessoas cujas vidas refletem seu impacto. Por exemplo, a análise pode descrever o impacto de acordos comerciais que privilegiam as necessidades de grandes transnacionais agrícolas, e os testemunhos podem incluir aqueles de pequenos agricultores afetados por acordos comerciais. Outro exemplo é que a análise pode apontar para a crescente influência da medicina privada em um país em particular, e um testemunho pode descrever as maneiras pelas quais a medicina privada discrimina os pobres. A combinação de conhecimento acadêmico e experiência vivida promove o debate político a partir do qual as posições do MSP são desenvolvidas e, em seguida, consagradas nas declarações e convocatórias.

Um aspecto importante do trabalho do MSP é atuar como uma ponte entre o local e o global.
O MSP se engaja com muitos problemas globais, como descrito abaixo, mas permanece enraizado na preocupação com os problemas de saúde das comunidades locais. A análise e as ações realizadas localmente são baseadas no entendimento do capitalismo neoliberal globalizado. O MSP também leva as preocupações locais para o nível global, como é feito nas Assembleias Mundiais de Saúde. Grande parte da conscientização e do aprendizado que acontece através do MSP está em fomentar a compreensão de como as dinâmicas econômicas e políticas globais, aparentemente distantes, afetam os problemas de saúde locais. Como exemplo, esse processo poderia incluir a análise de como os programas de saúde verticais, focados em doenças específicas e financiados por iniciativas público-privadas, que geralmente incluem grandes organizações filantrópicas, como a Fundação Gates, tiveram o efeito de desqualificar e debilitar os serviços de saúde pública, oferecendo melhores salários e reduzindo o grupo de pessoas disponíveis para serem empregadas nos sistemas nacionais de saúde ${ }^{16}$. Outro exemplo é conscientizar as comunidades que são impactadas 
pela mineração sobre como as empresas transnacionais podem fugir de suas responsabilidades com relação aos impactos negativos à saúde causados pela destruição do meio ambiente por meio da atividade de mineração.

\section{Como o MSP é governado}

Ao longo dos anos, houve um esforço sustentado para desenvolver uma estrutura de governança representativa, democrática e de tomada de decisões para o Movimento, que é, principalmente, uma rede de redes.

O cenário principal de tomada de decisão do MSP é a Assembleia da Saúde dos Povos, onde se busca consenso por meio de debates. Entre essas reuniões, o MSP é governado por um Conselho Diretor Global (CDG) com dois copresidentes. O CDG é composto por representantes regionais e representantes de algumas das redes vinculadas, além de um representante do Conselho Consultivo. O CDG conta com o apoio de uma pequena secretaria, cujos membros recebem salários modestos. Em 2019, o secretariado estava localizado em três locais: Cidade do Cabo (África do Sul), Delhi (Índia) e Bruxelas (Bélgica). O CDG possui uma comissão de coordenação (7 membros) que se reúne mensalmente, geralmente via Skype, e toma as decisões do dia a dia do MSP. Também possui um Conselho Consultivo, que inclui pessoas que já prestaram um longo serviço ao movimento e são convidadas pelo CDG a participar.

O MSP também estabeleceu grupos de campanha para desenvolver e mobilizar em torno de temas transversais e globais. Os seis temas atuais de campanha foram desenvolvidos e adotados na $4^{\mathrm{a}}$ Assembleia da Saúde dos Povos:

- Justiça de gênero e saúde

- Meio ambiente e saúde dos ecossistemas

- Nutrição e soberania alimentar

- Comércio e saúde
- Sistemas de saúde equitativos

- Guerra e conflito, ocupação, migração forçada e saúde

Esses temas enquadram as campanhas do MSP nos círculos dos países e no âmbito mundial. Essas campanhas refletem questões que são relevantes na esfera global, com impactos locais. O MSP reúne conhecimento desde essas duas perspectivas, global e local. Campanhas e grupos adicionais podem surgir à medida que novos desafios e percepções emergem. Essas questões não excluem o desenvolvimento de campanhas nos países sobre os prementes desafios nacionais de saúde.

A governança de cada círculo de país é variada. Emum extremo, está a África do Sul, ondeo MSPé uma organização registrada, enquanto na maioria dos outros locais o círculo é uma rede informal de indivíduos e organizações afins. Os círculos nos países variam em tamanho, de algumas poucas pessoas, em alguns países, até o enorme MSP na Índia. O MSP na Índia (conhecido no vernáculo local como Jan Swasthya Abhiyan - JSA) é uma coalizão de 22 redes nacionais, alianças, movimentos, grupos de referência e federação de ONGs, que se centram na saúde, no desenvolvimento, na ciência, nas questões das mulheres, nos direitos à saúde de crianças e pessoas marginalizadas e problemas de saúde ambiental. Um Comitê Coordenador Nacional da JSA, com redes e representantes no nível provincial, planeja e organiza diferentes campanhas e iniciativas sobre vários aspectos da política de saúde. Diferentes estados desenvolveram suas próprias redes, que se concentram nas políticas e nos desafios da saúde regionais, enquanto seguem participando de campanhas nacionais.

Os círculos de países são agrupados em grupos regionais para incentivar a coordenação intra e inter-regional e o compartilhamento de informações. Para 2019, essas regiões são: Sudeste Asiático e Austrália, Sul da Ásia, Índia (JSA), África Ocidental e Central, África Oriental e Meridional, Oriente Médio, América Latina (que compreende quatro sub-regiões), América do Norte e 
Europa. Cada um desses grupos regionais nomeia representantes para o CDG.

\section{Grandes campanhas globais do movimento}

Globalmente, além dos seis temas de campanha listados anteriormente, o MSP tem uma série de iniciativas de longa data, projetadas para influenciar debates e ações de saúde globalmente.

\section{Relatório Alternativo da Saúde Mun- dial - Global Health Watch}

O MSP, em coordenação com várias outras redes, produz um 'Relatório Alternativo de Saúde Mundial' independente e regular, conhecido por seu nome em inglês Global Health Watch (GHW). Foram publicados cinco desses relatórios, e o sexto está previsto para meados de 2021. Cada edição do GHW é diferente e é um exercício colaborativo que envolve um grande número de pessoas, instituições acadêmicas e organizações

que compartilham o desejo de melhorar o estado da saúde mundial e expressar solidariedade com a necessidade de abordar a injustiça social e política, aspectos subjacentes à saúde precária"1.

O GHW $\mathbf{5}^{\mathbf{1 7}}$ teve contribuições de mais de 120 pessoas e 70 organizações de todo o mundo. Cada GHW contém seções que analisam o contexto político-econômico da saúde global, os determinantes sociais-chave, tendências nos sistemas de saúde e também inclui uma seção intitulada 'Observatório', na qual se revisam criticamente o governo, as agências de ajuda internacionais, as agências e fundações de saúde e desenvolvimento. No mais recente GHW, há uma seção intitulada 'Resistência', onde são apresentadas campanhas e iniciativas inspiradoras e inovadoras para fortalecer o MSP em diferentes países e em todo o mundo. O conteúdo do GHW 5 é mostrado no quadro 3.

Quadro 3. Resumo dos principais conteúdos do GHW 5

A arquitetura política e econômica global

- Objetivos de Desenvolvimento Sustentável na era do neoliberalismo

- 'Não deixar ninguém para trás': São os ODS o caminho a seguir?

- Avanços e retrocessos rumo a um sistema único de saúde pública na América Latina

- Raízes estruturais da migração

Sistemas de saúde: problemas atuais e debates

- Cobertura universal de saúde: apenas sobre a proteção financeira?

- Revitalizando o controle da comunidade na atenção primária à saúde

- Cuidados de saúde nos EUA: entendimento do complexo médico-industrial

- Contextualizando a luta dos trabalhadores da saúde na África do Sul

- O 'Novo' Hospital Karolinska: como as PPPs enfraquecem os serviços públicos

- Acesso dos imigrantes aos cuidados de saúde na União Europeia

- Informalização do emprego em serviços públicos de saúde no Sul da Ásia

Além da atenção médica

- Mudanças climáticas, degradação ambiental e saúde: confrontando as realidades

- Enfoque de gênero para a saúde e os direitos sexuais e reprodutivos

- Reformas de saúde no Chile: falta de progresso nos direitos e na saúde sexual e reprodutiva das mulheres

- Acordos comerciais e saúde dos trabalhadores

- Saúde pública no setor extrativo na África Oriental e Austrália

- A guerra às drogas: da aplicação da lei à saúde pública 
Quadro 3. (cont.)

Vigilância

- O dinheiro fala mais alto na Organização Mundial da Saúde

- Fundações filantrópicas privadas: o que significam para a saúde global?

- Empresas de consultoria de gestão em saúde global

- Gavi e Fundo Global: as estruturas de governança privada enfraquecem a supervisão pública nas parcerias público-

-privadas

- Tratados de investimento: obrigam aos governos o resgate

- Enquadrando a saúde como uma questão de segurança

- Política de dados, informações e conhecimento

- Acesso e distribuição de benefícios: o marco de preparação para a pandemia de influenza

- Programas de saneamento total às custas da dignidade humana

Resistência, ações e mudanças

- Os movimentos sociais defendem as reformas progressistas da saúde em El Salvador

- Contestações sobre o manejo da desnutrição aguda grave na Índia

- Pessoas vivendo com HIV na Índia: a luta pelo acesso

- Compromisso comunitário na luta pela saúde na Itália

Fonjte: GHW ${ }^{17}$.

\section{Observatório da Organização Mun- dial da Saúde (WHO Watch)}

A formação do MSP deveu-se, em grande parte, a uma decepção com o papel da OMS nos anos anteriores a 2000. Essas decepções foram registradas na Carta da Saúde dos Povos e exigiam:

uma transformação radical da Organização Mundial da Saúde (OMS), para responder aos desafios da saúde de uma maneira que beneficie os pobres, evite os enfoques verticais, assegure o trabalho intersetorial, envolva as organizações populares na Assembleia Mundial da Saúde e garanta a independência de interesses empresariais ${ }^{\mathbf{1 8}}$.

As frustrações do MSP continuaram e resultaram em um compromisso regular com a OMS. Inicialmente, um Círculo de Advocacia junto à OMS incluiu a participação anual na sessão do Fórum de ONGs para a Saúde na Assembleia Mundial da Saúde (AMS) e um briefing técnico sobre o MSP e a Carta de Saúde dos Povos em 2003. Mais tarde, o MSP estabeleceu o WHO Watch, através do qual membros selecionados do MSP participam anualmente da reunião do Conselho Executivo da OMS, em janeiro, e da Assembleia Mundial da Saúde, em maio. Os observadores em campo tendem a ser membros mais jovens, e, portanto, o processo é um excelente campo de treinamento e um veículo de recrutamento para o MSP. A profunda análise da política é apoiada por membros experientes do MSP. Através de seus esforços combinados, e com o apoio dos membros do MSP em todo o mundo, elaboram-se críticas detalhadas, perspicazes e relevantes às orientações das resoluções e declarações submetidas às estruturas de governo da OMS, as quais estão disponíveis on-line. As devoluções de vários atores políticos, de países de baixa e média renda, sugerem que os comentários do MSP são imensamente úteis para ajudá-los a redigir suas respostas com relação às políticas, e um deles comentou: "Nós usamos os produtos do WHO Watch muito bem"19(105).

O MSP também participa de outros eventos convocados pela OMS e faz comentários sobre os resultados. Por exemplo, um grupo de membros do MSP participou da 
Conferência da OMS sobre Promoção da Saúde em Helsinque e publicou uma declaração alternativa à oficial (https://phmovement.org/ phm-declaration-at-8th-global- conference-on-health-promotion-2013/). Também publicou uma declaração alternativa à Conferência Mundial da OMS sobre Determinantes Sociais da Saúde, realizada no Rio de Janeiro em 2011 (https://phmovement.org/alternative-civil-society-declaration-at-the-world-conference-on -os-determinantes-sociais-da-saúde-2011/).

\section{Universidade Internacional de Saúde dos Povos}

A Universidade Internacional da Saúde dos Povos (Uisp) é o principal programa de educação e desenvolvimento dos quadros do MSP. Desde 2005, a Uisp organiza cursos de curta duração em diferentes regiões do mundo para jovens ativistas da saúde e novos contatos do MSP. Esses cursos, que duram de alguns dias a duas semanas, são ministrados em diferentes idiomas e são organizados por diferentes círculos de países e instituições acadêmicas simpatizantes com a causa. Alguns são acreditados por universidades para programas de mestrado em Saúde Pública. O corpo docente é composto de membros e ativistas do MSP, que compartilham suas opiniões, suas experiências de vida e lutas para inspirar os participantes.

Os objetivos típicos de um curso da Uisp são mostrados no quadro 4.

Quadro 4. Objetivos de um curso da Uisp

Aprofundar a compreensão de:

- vínculos entre meio ambiente e saúde;

- globalização e economia política da saúde;

- relações de gênero e saúde;

- determinantes sociais da saúde.

Conhecer as políticas de serviços de saúde, incluindo atenção primaria à saúde e os sistemas de saúde com uma perspectiva crítica sobre 'reformas do setor de saúde';

Compreender a aplicação de um enfoque baseado em direitos nas questões de saúde;

Possibilitar a avaliação crítica da 'assistência para o desenvolvimento da reforma de saúde';

Encorajar a exploração do significado da espiritualidade no ativismo e na mudança social;

Desenvolver habilidades práticas e conceitos que permitam aos ativistas serem mais efetivos no amplo movimento pela equidade em saúde.

Fonte: www.iphu.org20

Embora a avaliação da Uisp tenha estabelecido que a maioria dos participantes considerou esses cursos inspiradores, temos observado um êxito parcial no resultado quanto à participação ativa dos participantes do curso no MSP do seu país de origem. Enquanto alguns o fazem, fica claro que um maior acompanhamento após os cursos poderia aumentar o grau em que isso acontece ${ }^{19}$.

\section{Campanha de saúde para todos}

Esta campanha tem a ver com a realização do direito à saúde em âmbito nacional e mundial.
O site do MSP informa que a campanha é um marco de organização global para diferentes ações de mobilização de redes da sociedade civil e movimentos sociais em todo o mundo e tem como objetivo informar e influenciar os governos a abordar as deficiências estruturais e sistêmica no sistema de saúde.

Na prática, isso geralmente se traduz em círculos nacionais que desenvolvem ou participam de ações para enfrentar os principais desafios atuais da saúde, que são diferentes em cada país. Tais ações são tão diversas, indo desde uma campanha recente em Gana para melhorar o saneamento 
após uma epidemia de cólera a uma campanha em andamento para um 'Seguro Nacional de Saúde dos Povos', liderada pelo MSP da África do Sul, ou a uma campanha em andamento na Austrália, para manter e definir o sistema nacional de saúde pública, ou uma campanha no Reino Unido para defender o Serviço Nacional de Saúde. Além disso, os seis temas da campanha descritos acima oferecem aos círculos do país possíveis focos adicionais para se organizarem.

O MSP vem refletindo sobre seu ativismo para alcançar a Saúde para Todos. Isso é percebido em seu recente trabalho de pesquisa financiado pelo Centro Internacional de Pesquisa em Desenvolvimento do Canadá (IDRC). Esse apoio determinou que o MSP promovesse, a partir de 2014, um grande estudo multicêntrico que avaliou a participação da sociedade civil na luta pela 'Saúde para Todos'. Durante quatro anos, 130 pesquisadores ativistas em 10 países produziram 50 relatórios de pesquisa e um relatório geral ao final do trabalho ${ }^{19}$.

\section{Incluindo os determinantes sociais da saúde na agenda da OMS}

O MSP foi um dos grupos que advogou pelo estabelecimento de um grupo da OMS que considerasse o que era necessário para alcançar maior equidade em saúde. A resposta da OMS sob o então diretor geral Dr. Lee foi estabelecer a Comissão de Determinantes Sociais da Saúde (CDSS). Um dos indicados pelo MSP para essa Comissão foi nomeado integrante da Comissão, e, assim, o MSP participou de maneira central no engajamento da CDSS com os grupos da sociedade civil. Além disso, os ativistas e apoiadores do MSP eram membros de várias das nove redes de conhecimento criadas para realizar o trabalho aprofundado da Comissão. A participação do MSP se refletiu na natureza relativamente progressiva do relatório do CDSS, que incluía chamar a atenção para acordos comerciais globais injustos, para a prestação de contas das empresas transnacionais e a ação sobre a distribuição desigual de poder, dinheiro e dos recursos que sustentam as iniquidades em saúde global. Nos 11 anos desde o relatório do CDSS, houve um progresso limitado na implementação de suas recomendações, mas na recente Assembleia Mundial da Saúde (maio de 2019), a OMS anunciou que estava estabelecendo uma Divisão para Populações Mais Saudáveis, com um ramo dedicado aos determinantes sociais da saúde.

Os membros e apoiadores do MSP também participaram do desenvolvimento do Relatório sobre a Saúde Mundial, em 2008, sobre atenção primária à saúde, pelo trigésimo aniversário da Declaração de Alma-Ata, que incluiu facilitar uma sessão técnica para a OMS, contribuir com alguns capítulos e revisar o relatório antes de sua conclusão. O MSP também foi convidado a participar do seu lançamento, na cidade de Alma-Ata, Cazaquistão, e a falar em um painel de discussão. Da mesma forma, o MSP foi convidado a participar como membro do Grupo Consultivo Internacional para a Conferência Mundial de Atenção Primária à Saúde para Cobertura Universal de Saúde, por ocasião do $40^{\circ}$ aniversário da Declaração de Alma-Ata, realizada em Astana, Cazaquistão, em outubro de 2018. O MSP manifestou preocupação com a Declaração oficial de Astana, por meio de uma declaração da sociedade civil assinada por várias centenas de organizações e indivíduos (https://phmovement. org/alternative-civil-society-astana-declaração sobre cuidados primários de saúde/).

\section{Exemplos de ação nos países}

O MSP se constrói organicamente com os movimentos de base em todo o mundo. Os problemas gerais apresentados no quadro 2 se traduzem em um enorme impacto na saúde das comunidades locais. Portanto, um componente vital da rede MSP são os círculos de seus países. Em meados de 2019, havia aproximadamente 70 círculos de países ativos. Exemplos de ações recentes organizadas pelos círculos de países incluem:

África do Sul: A África do Sul sofre uma carga extremamente alta de doenças, incluindo a maior epidemia de HIV/Aids do mundo, 
problemas persistentes de saúde materna e infantil e uma crescente epidemia de doenças não transmissíveis. Possui um sistema de saúde segmentado, um público e outro privado. Este último abriga a maioria do pessoal de saúde qualificado do País, cobre menos de $20 \%$ da população, possui uma distribuição inadequada de provedores e instalações, oferta de serviços e falta de controle social. Os serviços de saúde do setor público, que prestam serviços à maioria, são fracos nos níveis primário e comunitário e têm cobertura e qualidade variáveis. Muitas instalações sofrem grande escassez de pessoal e governança e gerenciamento abaixo do ideal. Em resposta a esses desafios, o governo desenvolveu uma política chamada 'esquema de Seguro Nacional de Saúde (SNS)', para fornecer Cobertura Universal de Saúde (CUS) através de um sistema de pagamento único que comprará serviços de fornecedores públicos e privados credenciados. O MSP África do Sul (MSP SA) desempenhou um papel de liderança entre as organizações da sociedade civil na mobilização de um 'Seguro Nacional de Saúde do Povo', cujas principais características são solidariedade social, equidade, atenção integral e participação comunitária. Embora o projeto de lei do SNS, recentemente legislado, defenda esses princípios, o MSP África do Sul está preocupado com o fato do lobby do setor privado ser cada vez mais influente, conduzindo a um esquema caracterizado por um acordo de múltiplos pagadores e uma cobertura diferencial de subgrupos com diferentes condições de trabalho. A campanha do SNS para o Povo está constantemente ganhando espaço, e o MSP está sendo chamado dentro e fora do País para assessorar sobre possíveis armadilhas da CUS.

Índia: Começando com a preparação de cinco pequenos folhetos como recurso para $o$ movimento em 2000, depois publicados como livro ${ }^{21}$, o JSA (MSP Índia) se comprometeu com a revisão da Política Nacional de Saúde em 2002, alertando contra a legitimação da privatização e comercialização dos cuidados de saúde no
País22. Uma série de audiências públicas foi organizada com a Comissão Nacional de Direitos Humanos sobre a negação do direito à atenção médica. O compromisso contínuo do JSA, de várias maneiras, resultou na Missão Nacional de Saúde Rural. O JSA continua a participar da ação e do diálogo sobre políticas de saúde, à medida que o País desenvolve sua resposta ao esquema de Cobertura Universal de Saúde. Muitas redes estatais do JSA estão respondendo a desafios que incluem a disponibilidade de medicamentos essenciais, neutralizar a comercialização e a mercantilização da atenção médica e prevenir a privatização de unidades de vacinação e, ao mesmo tempo, promover a ação comunitária para a saúde.

Austrália: A ação incluiu uma campanha contra a introdução de copagamentos aos usuários do plano nacional de seguro nacional de saúde Medicare, fazendo lobby para melhorar o financiamento dos serviços de saúde controlados pela comunidade aborígine e uma campanha contra acordos comerciais que ameaçam a saúde.

Escócia: realizou uma assembleia de saúde aberta, na qual os participantes pediram propostas concretas de ação coletiva para reduzir as iniquidades em saúde. Isso levou o MSP Escócia a desenvolver um Manifesto de Saúde para os escoceses, através de um enfoque que combina a pesquisa-ação participativa e a defesa proativa da saúde pública.

Europa: os círculos dos países participaram do protesto e da conferência 'Nossa saúde não está à venda!', realizada em Bruxelas, organizada pela Rede Europeia contra a Comercialização, Privatização da Saúde e Proteção Social. Ativistas de grupos MSP na Bélgica, Itália, Croácia e França se uniram em ambos os eventos, juntamente com membros de outras redes, incluindo sindicatos e grupos de pacientes.

Os círculos nacionais do MSP estão respaldados por um manual interativo 'Como construir um movimento para a saúde - uma ferramenta para ativistas da saúde' (https:// twha.be/PHM-manual). Esse manual descreve a filosofia do MSP e fornece conselhos práticos, apoiados por muitos exemplos de como 
atuar em apoio às questões da saúde. Enfatiza o valor do desenvolvimento de redes e coalizões com outros grupos, de outros setores, como aqueles que se mobilizam em torno do meio ambiente, do direito à água, soberania alimentar, e com os sindicatos, pequenos agricultores e o movimento de mulheres, para fazer campanhas sobre temas de interesse mútuo.

\section{Desafios enfrentados pelo MSP}

Como qualquer movimento social, o MSP enfrenta uma série de dilemas organizativos e relacionados às suas agendas de campanhas. Alguns dos mais importantes são analisados a seguir.

\section{O MSP é um movimento popular ou profissional?}

O MSP é um movimento de ativistas comprometidos. Muitos ativistas do MSP são profissionais de saúde que trabalham diretamente com comunidades ou acadêmicos progressistas. Por sua natureza, os programas globais inevitavelmente envolvem predominantemente profissionais e acadêmicos. Porém, em vários países, especialmente no sul da Ásia e na América Latina, há um número significativo de profissionais e ativistas da comunidade. Às vezes, há tensões experimentadas como resultado das diferentes origens dos membros, que vão desde diferentes ênfases no planejamento de ações até diferentes necessidades em termos de recursos necessários para participar ativamente nos círculos nacionais. Apesar desses desafios, o MSP está continuamente explorando maneiras de aumentar a diversidade de sua base. Em geral, isso tem sido mais fácil em situações em que o ritmo da luta se acelera e há uma participação mais ampla dos cidadãos.

\section{Idioma}

O MSP se esforça para trabalhar em vários idiomas, sendo os dois principais o inglês e o espanhol. A Carta da Saúde dos Povos foi traduzida para mais de 40 idiomas, incluindo Farsi, Guarani, Hausa, Ndebele, Quechua, Serer e Wolof. A maioria está disponível no site do MSP. Nas Assembleias de Saúde dos Povos, realizam-se esforços para traduzir para tantos idiomas quanto for possível, com o apoio de tradutores de interesse público que trabalham para organizações como a Babel.

\section{Financiamento: coordenação global com pouco dinheiro}

O MSP Global depende de doações de seus membros e algumas pequenas contribuições de redes de apoio. Nos últimos anos, o MSP também atraiu fundos básicos de doadores, como o Oxfam Novib e a Open Society Foundation. Mais recentemente, os fundos dos doadores foram garantidos para projetos específicos, como o fortalecimento da governança global da saúde, que parcialmente financiou o GHW e o WHO Watch, e para apoiar as Assembleias de Saúde dos Povos. O MSP conseguiu manter um pequeno secretariado global descentralizado, mas a maioria das atividades do MSP é resultado do esforço voluntário. Os programas GHW, WHO Watch e Uisp contam com apoiadores do MSP que doam seu tempo sem qualquer gratificação financeira. Aqueles que estão nas estruturas de governança do Movimento também são voluntários.

Os círculos de países também são impulsionados por esforços voluntários. Alguns círculos, como o da África do Sul e da Índia, podem contratar funcionários. Foram obtidos fundos para um trabalhador de divulgação africano que teve êxito em facilitar novos círculos de países nessa região. A recente revisão feita na pesquisa sobre a contribuição da sociedade civil no trabalho para a Saúde para Todos concluiu com recomendações para organizações que financiam a sociedade civil ${ }^{19}$. Esses fundos básicos sugeridos em apoio ao movimento 
social da sociedade civil deveriam ser proporcionados para fortalecer os tipos de processos nacionais e globais descritos neste artigo; processos que, em última instância, contribuem para melhorar a saúde no mundo. O relatório também recomendou que os financiadores devem conhecer os limites e riscos associados ao financiamento de projetos estritamente específicos. Em vez de acordos de financiamento tão rígidos, o relatório recomendou que a responsabilidade deve basear-se em uma avaliação das direções centrais da organização e sua integridade.

\section{Organização registrada ou rede de redes?}

Um debate não resolvido dentro do Movimento refere-se a se o MSP deve ou não desenvolver opções para filiação individual e organizacional e se tornar uma organização legalmente registrada. Alguns argumentam que o movimento é melhor como uma rede de redes, enquanto outros argumentam que a filiação com uma escala progressiva de tarifas poderia permitir ao movimento ser mais autossuficiente e favorecer uma representação mais estruturada e com maior responsabilização dos representantes.

\section{Conclusões}

Nos quase vinte anos de sua existência, o MSP se tornou uma das vozes internacionais mais poderosas, apresentando uma alternativa progressista ao regime neoliberal dominante que governa o discurso e as direções da saúde e do desenvolvimento. Sempre se manifestou desde a perspectiva de povos e comunidades oprimidas e tem argumentado que a saúde das pessoas e do ecossistema, bem como a busca de equidade, devem ter prioridade sobre a busca de ganhos privados. Seu papel permanente de dizer a verdade ao poder é mais do que nunca necessário, em uma época em que as desigualdades aumentam e o poder se concentra rapidamente entre as pessoas e corporações mais ricas do mundo. Sua visão de um mundo centrada nas pessoas e no ecossistema oferece perspectivas muito melhores para a equidade em saúde.

\section{Colaboradores}

Baum F (0000-0002-2294-1368)*, Sanders D (0000-0003-1094-7655)*, Narayan R (00000002-2018-1537)* contribuíram igualmente para a elaboração do manuscrito.
*Orcid (Open Researcher and Contributor ID).

\section{Referências}

1. World Health Organization. Declaration of Alma-Ata. International Conference on Primary Health Care [internet].Alma-Ata: WHO; 1978.[accessed on 2018 Jan 2].Available on:http://www.who.int/publications/almaata_declaration_en.pdf?ua=1.
2. Walsh JA, Warren KS. Selective primary health care: an interim strategy for disease control in developing countries. N Engl J Med. 1979;301(18):967-74.

3. Harvey D. A brief history of neoliberalism. Oxford: Oxford University Press; 2005. 
4. Rudin J, Sanders D. Debt, structural adjustment and health. In: Benatar S, Brock G, editors. Global Health and Global Health Ethics. Cambridge: Cambridge University Press; 2011. p. 155-65.

5. Wade RH. Global growth, inequality, and poverty: the globalization argument and the political" science of economics. In: Ravenhill J, editor. Global Political Economy. 5.ed. Oxford: Oxford University Press; 2017. p. 319-55.

6. Velásquez G. Public-private partnerships in global health: putting business before health? Geneva: South Centre; 2014.

7. Narayan R, Schuftan C. People's Health Movement. In: Heggenhougen K, Quah S, editors. International Encyclopedia of Public Health.San Diego: Academic Press; 2008. p. 41-5. v. 5.

8. Narayan R. The role of the People's Health Movement in putting the social determinants of health on the global agenda. Health Promot J Austr [internet]. 2006[accessed on 2017 Oct 24]; 17(3):186-188. Available on:http://search.informit.com.au/documentSu mmary; $\mathrm{dn}=452806502349673$;res=IELHEA $>$ ISS.

9. Chowdhury Z, Rowson M. The People's Health Assembly. Revitalising the promise of "Health for All". BMJ. 2000;321(7273):1361-2.

10. Schuftan C, Turiano L, Shukla A. The right to health: A People's Health Movement perspective and case study. In: Clapham A, Robinson M, Mahon C, et al, editors. Swiss Human Rights Book.Zurich: Rueffer\& Rub Sachbuchverlag; 2009. p. 521-3.v. 3.

11. People's Health Movement; Medact; Global Equity Gauge Alliance. Global Health Watch 1 (2005-2006): An alternative world health report. London: UK: Zed Books; 2005.

12. People's Health Movement. The People's Charter for Health [internet]. 2000. [accessed on 2018 Jan 2]. Available on: http://www.phmovement.org/en/resources/charters/peopleshealth?destination=home.
13. People's Health Movement, editor. The Second People's Health Assembly. Cuenca: PHM; 2005.

14. People's Health Movement. The final Cape Town call to action [internet]. 2012. [accessed on 2014 Dec 1]. Available on: http://www.phmovement.org/en/pha3/ final_cape_town_call_to_action.

15. People's Health Movement, editor. The Struggle for Health is the Struggle for a More Equitable, Just and Caring World [internet]. 2018. [accessed on 2014 Dec 1]. Available on: https://phmovement.org/declaration-pha4/.

16. Cailhol J, Craveiro I, Madede T, et al. Analysis of human resources for health strategies and policies in 5 countries in Sub-Saharan Africa, in response to GFATM and PEPFAR-funded HIV-activities. Global Health. 2013;9(1):52-66.

17. People's Health Movement, Medact, Health Action International, et al. Global Health Watch 5: An Alternative World Health Report. London: UK: Zed Books; 2017.

18. People's Health Assembly. People's Health Charter [internet]. 2001. [accessed on 2007 Apr 10]. Available on: http://www.phmovement.org/files/phm-pch-english.pdf.

19. Bodini C, Sanders D, Sengupta A. The Contribution of Civil Society Engagement to the Achievement of Health for All. Cape Town: People's Health Movement; 2018.

20. International People's Health University. International People's Health University [internet].2019. [accessed on 2019 Jun 3]. Available on: https://www.iphu.org/.

21. AbiyanJS. Health For All Now! The People's Health Source Book. Chennai: South Vision; 2000.

22. AbiyanJS.National Health Policy 2001 - Legitimising Privatization. Delhi: Delhi Science Forum; 2001.

\footnotetext{
Recebido em 18/07/2019

Aprovado em 03/11/2019

Conflito de interesses: inexistente
}

Suporte financeiro: não houve 